\title{
Modelling the Use of Traditional Family Planning by Women in Sri Lanka
}

\author{
Peiris,T.S.G. ${ }^{1} \&$ Karunarathne, H.V.V.M.P. ${ }^{2}$ \\ sarath.p@sliit.1k,migara@demo.cmb.ac.1k \\ School of Mathematics and Statistics, Faculty of Humanities and Sciences, SLIIT, Malabe, Sri Lanka \\ Department of Demography, Faculty of Education, University of Colombo, Colombo, Sri Lanka
}

\begin{abstract}
Family planning plays a crucial role in enhancing the health of the mother and the child. Contraceptives are used by most women in the reproductive age span (15- 49 years). Sri Lanka has been named as one of the countries with high usage of traditional family planning (TFP) methods than the other Asian countries. However, the reasons for that have not been investigated. Therefore, this study is carried out to identify the significant factors influencing on usage of TFP by using data from Sri Lanka Demographic and Health Survey in 2016 with a sample size of 10835. The percentages of women using TFP is $16.3 \%$ compared to $83.7 \%$ of using modern family planning (MFP). Among TFP users, the withdrawal method and the rhythm method are $35 \%$ and $57 \%$ respectively. The balance $8 \%$ uses both methods. A binary logistic regression model was developed to capture the factors influencing the use of TFP by considering all variables simultaneously. The fitted model was invariant on the type of selection method and selection criteria. The overall predictive power is $82.9 \%$. The knowledge on family planning, having advice from public health midwives, attendance to well-women clinics, religion, ethnicity, decision to use family planning, husband's occupation, women's age, women's occupation, women's education level, number of children, and wealth quantile are the significantly associated factors with the usage of TFP. The odds of the usage of TFP among the women having no children and women having 1 or 2 children are respectively 1.4 and 4.0 times higher than the women having 3 or more children. The factors identified are geared towards providing robust evidence based on data driven decision making (DDDM) and therefore the key population groups in need of contraceptive services can be targeted more effectively and efficiently. Organizing counselling programmes and promotions on family planning and conducting media awareness programmes to avoid some myths on modern contraceptives can be suggested.
\end{abstract}

Keywords: Binary Logistic Regression, Education Level, Odd Ratio, Traditional Family Planning Methods 


\section{Introduction}

Family planning in global context plays a crucial role in enhancing the health of both the mother and the child. Growing demands for contraceptive utilization from both genders is to limit, space, or delay the number of births and size of the family. Different contraceptive methods are used by women in the reproductive age span between 15-49 years age (United Nations, 2017). It further indicates that $63 \%$ of women use some form of a family planning method which varies from $70 \%$ in Europe countries to $25 \%$ in Western African countries.

In 1965, a national program for family planning was introduced in Sri Lanka and later it was integrated to the maternal and child health activities of the Ministry of Health in Sri Lanka. With the establishment of the Family Health Bureau in 1968 and the implementation of family planning services and training, Sri Lanka became one of the best states in South Asia in implementing family planning practices (United Nations, 2017).

\section{Family Planning}

Family planning is defined as 'the ability of individuals and couples to anticipate and attain their desired number of children and the spacing and timing of their births (WHO, 2020) and it is divided into two categories namely, (i) traditional family planning and (ii) modern family planning (MFP) (UN, 2019). According to the Sri Lanka Demographic and Health Survey (2016), withdrawal and rhythm methods are the two TFP methods in Sri Lanka. Globally MFP methods prevent about onethird of pregnancy-related deaths, as well as $44 \%$ of neonatal deaths. In contrast, the failure rate of TFP methods is recorded as high. It can affect mother and child health, especially unwanted pregnancies, teenage pregnancies, abortions, maternal deaths, premature births etc. (Gunawardena\& Hettiarachchi, 2012).

The contraceptive methods help to prevent the transmission of HIV/AIDS and other sexually transmitted infections, but traditional methods are not capable of protecting people from these infections (Shaw, 2010). It shows that there is a risk for having sexually transmitted infections for those who are using TFP methods. Sri Lanka has been identified as one of the countries with high proportions (15-21\%) of women who depend on TFP methods than the MFP methods (Singh et al., 1997). An extensive literature survey carried out by Karunaratna (2020) claimed that the factors influencing the use of TFP have not been studied in Sri Lanka, though the required data has been already collected from various surveys.

Therefore, the objective of this study is to identify the significantly influential factors on usage of TFP by women and develop a model to predict the percentage of the use of TFP method under different conditions.

\section{Materials and Methods Survey Procedure}

This study is based on the secondary data gathered from Sri Lanka Demographic and Health Survey - SLDHS (2016) conducted by the Department of Census and Statistics, Ministry of National Policies and Economic Affairs and Ministry of Health, Nutrition and Indigenous Medicine. This SLDHS 2016 survey is the $5^{\text {th }}$ survey conducted in Sri 
Lanka with the objective of finding out the recent data to monitor and evaluate the impact of population, health and nutrition programs employed by different government agencies in Sri Lanka.

The sampling procedure of the SLDHS 2016 is a two-stage stratified sampling design. At the first stage 2500 census blocks were selected as primary sampling units and 12 housing units were selected from each selected primary sampling units as the secondary sampling units. A total of 28,800 housing units have been selected for the survey. Among them 27,210 were enumerated and detailed information was collected from all ever-married women aged between 15 - 49 years and finally 18,302 ever married women were successfully interviewed.

\section{Data collection}

Data for the SLDHS was collected through a questionnaire from household and eligible women through personal interviews. Questionnaire had two main sections namely household and another section on women and children. The women and children section were used to collect data from ever married women aged 15 - 49 years. Under this section, data were collected on 12 sub sections such as, background characteristics, reproductive history, knowledge and use of family planning methods, pregnancy and postnatal care, child immunization, health and nutrition, fertility preferences, husband's background and wife's employment, awareness about AIDS and other sexually transmitted infections (STIs), awareness about well-women clinics, children who need special care (disabled), early childhood development and other health issues. Questionnaires were prepared in Sinhala and translated into Tamil and English languages.

\section{Data used for the study}

All women within the age between $15-49$ years those who are using family planning methods: namely TFP and MFP have been taken as the study sample through SLDHS-2016 survey. This study sample covered all the districts, urban and rural state sectors in Sri Lanka. Therefore, the total sample is 10,835 women who are within the age 15 - 49 years using family planning methods.

\section{Variables used}

The dependent variable is the status of use of TFP method ( $1=$ yes, $0=$ no). The details of independent variables are given in Table 1. 
Table 1.

\section{Selected variables for this study}

\begin{tabular}{|c|c|c|}
\hline Variable & Levels & $\begin{array}{l}\text { Code Used for } \\
\text { the analysis }\end{array}$ \\
\hline \multirow{4}{*}{$\begin{array}{l}\text { Women's age } \\
\text { (in years) }\end{array}$} & $1-` 42-50 ’$ & WA1 \\
\hline & $2-' 33-41 '$ & WA2 \\
\hline & $3-' 24-32 ’$ & WA3 \\
\hline & $4-' 15-23 ’$ & WA4 \\
\hline \multirow{3}{*}{$\begin{array}{l}\text { Husband's age } \\
\text { (in years) }\end{array}$} & $1-' 49-63 ’$ & HA1 \\
\hline & $2-{ }^{\prime} 34-48 '$ & HA2 \\
\hline & $3-' 19-33 ’$ & HA3 \\
\hline \multirow{3}{*}{ Marital status } & 1 - 'Married or living together' & MS1 \\
\hline & 2 - 'Divorce or separated' & MS2 \\
\hline & 3 - 'Widowed' & MS3 \\
\hline \multirow{3}{*}{ Number of children } & 1 - 'Childless' & $\mathrm{NC} 1$ \\
\hline & $2-$ ' 1 to 2 children' & $\mathrm{NC} 2$ \\
\hline & 3 - '3 or above children' & $\mathrm{NC3}$ \\
\hline \multirow{4}{*}{ Women's education level } & 1 - 'Degree \& above' & WE1 \\
\hline & 2 - 'Passed G.C.E A/L & WE2 \\
\hline & 3 - 'Passed grade 1 to G.C.E O/L & WE3 \\
\hline & 4 - 'No schooling or only pre school & WE4 \\
\hline \multirow{4}{*}{ Husband's education level } & 1 - 'Degree \& above' & HE1 \\
\hline & 2 - 'Passed G.C.E A/L & HE2 \\
\hline & 3 - 'Passed grade 1 to G.C.E O/L & HE3 \\
\hline & $4-{ }^{'}$ No schooling or only pre school & HE4 \\
\hline \multirow{3}{*}{ Residential sector } & 1 - 'Urban' & RS1 \\
\hline & 2 - 'Rural' & $\mathrm{RS} 2$ \\
\hline & 3 - 'Estate' & $\mathrm{RS} 3$ \\
\hline \multirow{3}{*}{$\begin{array}{l}{ }^{*} \text { Districts by family planning } \\
\text { usage }\end{array}$} & 1 - 'High usage districts' & DU1 \\
\hline & 2 - 'Moderate usage districts' & DU2 \\
\hline & 3 - 'Lowest usage districts' & DU3 \\
\hline \multirow{3}{*}{ *Knowledge of family plan } & 1 - 'Good' & FK1 \\
\hline & 2 - 'Moderate' & FK2 \\
\hline & 3 - 'Poor' & FK3 \\
\hline \multirow{4}{*}{ Decision to use FP } & 1 - 'My decision' & FD1 \\
\hline & 2 - 'Husband's decision' & FD2 \\
\hline & 3 - 'Decision of both' & FD3 \\
\hline & 4 - 'Decision of PHM' & FD4 \\
\hline
\end{tabular}


Table 1 (Continued)

\begin{tabular}{|c|c|c|}
\hline Ethnicity of women & $\begin{array}{l}1 \text { - 'Sinhala' } \\
2 \text { - 'Tamil' } \\
3 \text { - 'Muslim' } \\
4 \text { - 'Burger' }\end{array}$ & $\begin{array}{l}\text { RE1 } \\
\text { RE2 } \\
\text { RE3 } \\
\text { RE4 }\end{array}$ \\
\hline Religion of women & $\begin{array}{l}1 \text { - 'Buddhism' } \\
2 \text { - 'Catholic' } \\
3 \text { - 'Islam' } \\
4 \text { - 'Hindu' }\end{array}$ & $\begin{array}{l}\text { RR1 } \\
\text { RR2 } \\
\text { RR3 } \\
\text { RR4 }\end{array}$ \\
\hline Wealth quantile & $\begin{array}{l}1 \text { - 'Highest quantile' } \\
2 \text { - 'Lowest quantile' } \\
3 \text { - 'Middle quantile' }\end{array}$ & $\begin{array}{l}\text { WQ1 } \\
\text { WQ2 } \\
\text { WQ3 }\end{array}$ \\
\hline Women's occupation & $\begin{array}{l}\text { 1-'Manager, professional and } \\
\text { administrative jobs } \\
\text { 2-'Clerical, sales, industry and } \\
\text { machine related workers } \\
\text { 3- 'Unemployed' } \\
4 \text { - 'Eliminatory occupation' }\end{array}$ & $\begin{array}{l}\text { WO1 } \\
\text { WO2 } \\
\text { WO3 } \\
\text { WO4 }\end{array}$ \\
\hline Husband's occupation & $\begin{array}{l}\text { 1-'Manager, professional and administra- } \\
\text { tive jobs } \\
\text { 2- 'Clerical, sales, industry and machine re- } \\
\quad \text { lated workers } \\
3 \text { - 'Eliminatory occupation' } \\
4 \text { - 'Unemployed' }\end{array}$ & $\begin{array}{l}\mathrm{HO} 1 \\
\mathrm{HO} 2 \\
\mathrm{HO} 3 \\
\mathrm{HO} 4\end{array}$ \\
\hline Having advices from PHM & $\begin{array}{l}1-' \mathrm{No} ' \\
2-{ }^{\prime} Y e s '\end{array}$ & $\begin{array}{l}\text { AP1 } \\
\text { AP2 }\end{array}$ \\
\hline $\begin{array}{l}\text { Exposure to FP via electronic } \\
\text { media }\end{array}$ & $\begin{array}{l}1-{ }^{\prime} Y e s ' \\
2-' N o '\end{array}$ & $\begin{array}{l}\text { EE1 } \\
\text { EE2 }\end{array}$ \\
\hline $\begin{array}{l}\text { Exposure to FP via printed } \\
\text { media }\end{array}$ & $\begin{array}{l}1-' \mathrm{No} ' \\
2-' Y e s '\end{array}$ & $\begin{array}{l}\text { EP1 } \\
\text { EP2 }\end{array}$ \\
\hline $\begin{array}{l}\text { Exposure to FP via digital } \\
\text { media }\end{array}$ & $\begin{array}{l}1-' \mathrm{No} ' \\
2-' Y e s '\end{array}$ & $\begin{array}{l}\text { ED1 } \\
\text { ED2 }\end{array}$ \\
\hline Attend to well women clinic & $\begin{array}{l}1-\text { 'Yes' } \\
2-\text { 'No' } \\
3 \text { - 'Not aware' }\end{array}$ & $\begin{array}{l}\text { AW1 } \\
\text { AW2 } \\
\text { AW3 }\end{array}$ \\
\hline
\end{tabular}

*Variables were coded using criteria explained below 
Grouping district based on family planning usage (DU)

The categories of residential districts by family planning usage were also formulated by referring to the usage of contraceptives based on each district as given by the SLDHS report 2016. The three categories of DU (DU $=1, \mathrm{DU}=2 \& \mathrm{DU}=3$ ) respectively was based on the percentage of family planning usage: $\geq 70 \%, 40-70 \% \& \leq 40 \%$ respectively.

\section{Assessment of family planning knowledge (FK)}

The family planning knowledge was assessed using 12 questions asked from the women who responded to the SLDHS questionnaire. The questions had two answers as 'yes' and 'no'. Each correct and incorrect answers were scored as 1 and 0 respectively so that total marks for each respondent varied between 0 and 12. Based on the total score, respondents were categorized into three categories (1=good, 2=moderate and 3=poor) when the score was between 12-10, 9-5 and 4-0 respectively. Such details were discussed in the SLDHS report.

\section{Binary Logistic Regression Model}

As the dependent variable is binary, the binary the logistic regression model was fitted by taking all variables simultaneously. In binary logistics, log of odds of an event is considered as a linear impact from the explanatory variables, $X_{1}, X_{2}, \ldots, X p$. Thus, the fitted model is represented by the equation (1), where $p$ is the probability of using traditional family planning (that is the response variable $=1$ ). The data were analyzed using SPSS software. $\log ($ odds $)=\log (p /(1-p))=\beta_{0}+\beta_{1} X_{1}+\beta_{2} X_{2}+\cdots+\beta_{p} X_{p}$

\section{Results and Discussion}

\section{Distribution of two main family planning methods}

The analysis found that among the family planning users, the percentages of women using TFP and MFP are $16.3 \%$ and $83.7 \%$ respectively (Fig.1). Among the TFP users, the percentage of withdrawal method and rhythm method are $35 \%$ and $57 \%$ respectively. The balance $8 \%$ is the users of both methods.

\section{Figure 1.}

Distribution offamily planning (FP) methods

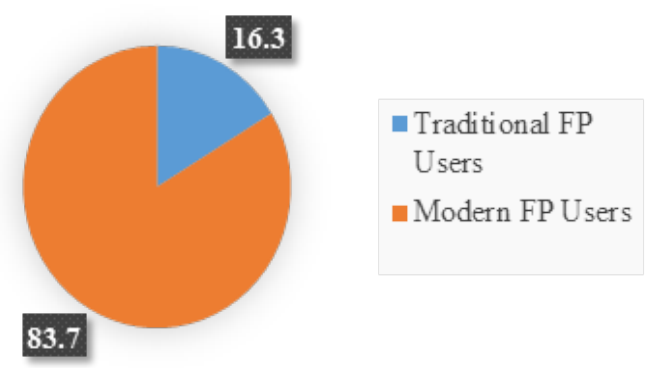

Distribution TFP and MFP users by age of women

Table 2.

Percentages TFP Users and MFP Users

\begin{tabular}{lcc}
\hline $\begin{array}{r}\text { Age categories of } \\
\text { women }\end{array}$ & $\begin{array}{c}\text { TFP } \\
\text { users } \\
(\%)\end{array}$ & $\begin{array}{c}\text { MFP } \\
\text { users } \\
(\%)\end{array}$ \\
\hline 15-23 years & 4.8 & 6.4 \\
\hline 24-32 years & 20.6 & 27.6 \\
\hline 33-41 years & 38.4 & 40.8 \\
\hline 42-50 years & 36.2 & 25.2 \\
\hline Total & 100.0 & 100.0
\end{tabular}


The percentages of MFP users in three lower age groups are higher than the corresponding percentages of TFP users confirming that the majority of the people below 41 years tends to use more MFP. However, as a notable point, the percentage of TFP method users is much higher than that of MFP method in the age category of $42-50$ years.

\section{Distribution of TFP and MFP users by status of advice from Public Health Midwives (PHM)}

Public health midwives play an active role in family planning promotions and advising on sexual and reproductive health practices for the married couples in Sri Lanka (SLDHS, 2016). According to fig. 2, among the TFP users, $37 \%$ only received advice from PHM compared to the corresponding $45 \%$ among MFP users.

\section{Figure 2.}

Percentage distribution of TFP and MFP users by the status of having advice (Y or N) from PHM

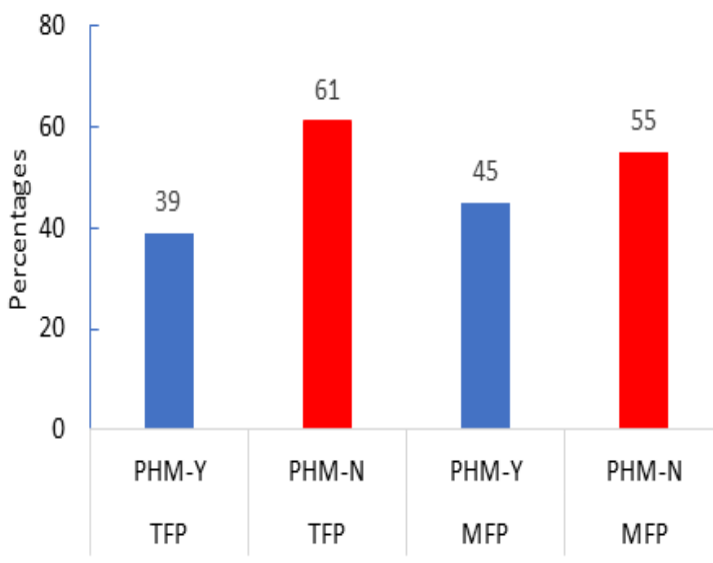

Distribution of TFP users and MFP users by the status- those who attend to WellWomen Clinics

Distribution of TFP users and MFP users based on their attendance at well-women clinics is shown in table 3 . Results revealed that nearly $53 \%$ among the TFP users do not attend well women clinics while $21.5 \%$ of TFP users are not aware of the well women clinics. However, $26 \%$ of TFP users attend well-women clinics close to their place of residence.

Table 3.

Distribution of TFP and MFP users by the status of attending to Well-Women Clinics

\begin{tabular}{lcc}
\hline $\begin{array}{l}\text { Attend to well women } \\
\text { Clinic }\end{array}$ & $\begin{array}{r}\text { TFP } \\
\text { Users }\end{array}$ & $\begin{array}{r}\text { MFP } \\
\text { Users }\end{array}$ \\
\hline Yes & 26.0 & 25.6 \\
\hline No & 52.5 & 45.2 \\
\hline Not aware & 21.5 & 29.2 \\
\hline Total & 100.0 & 100.0
\end{tabular}

On the other hand, $45.2 \%$ of MFP users do not attend women clinics and nearly $30 \%$ of respondents were not aware of the clinics. However, around $26 \%$ of MFP users attend well women clinics. It shows that MFP user's and TFP users' patterns of attending well women clinics are quite similar.

\section{Family Planning Knowledge and Awareness}

Family planning knowledge and awareness among TFP users and MFP users are shown in fig. 3. According to the results, $57.4 \%$ among the traditional family planning users possess a good knowledge regarding family planning and poor knowledge is shown only among $1 \%$ of TFP users. 


\section{Figure 3.}

\section{Distribution of Knowledge on Family Planning among TFP Users and MFP Users}

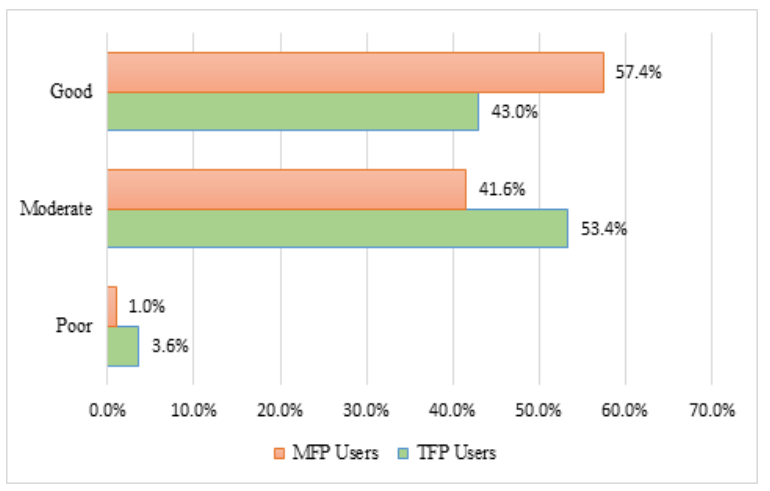

On the other hand, among the MFP users, more than fifty percent $(53.5 \%)$ of women possess moderate knowledge on family planning and $43 \%$ possess good knowledge. As a notable point, $3.6 \%$ of MFP users possess poor knowledge on family planning. It emphasizes that, traditional family planning users possess better knowledge on family planning compared to the MFP users.

\section{Modelling TFP}

The size and significance of the correlation coefficients based on the correlation matrix obtained for all variables in Table 1, using Spearman's rank correlation confirmed that there is no significant multicollinearity among variables. In order to find the significant variables when all variables are considered simultaneously, a binary logistic model was developed using both stepwise forward LR and stepwise forward Wald. The entry and removal probability were set as 0.05 and 0.051 respectively. The validity of the model was confirmed based on the non-significance of the Hossmer -Lemeshow test statistic. The significance of each variable was tested using the Wald test. It was noted that the standard errors of the significant variables are low.

Based on the results, it can be concluded with $95 \%$ confidence that the significant variables on TFP are knowledgeable on family planning (FK), the status of seeking advice from PHM (AP), attendance of women clinic (AW), religion (RR), ethnicity (RE), decision to use family planning (FD), husband's occupation (HO), age of the women (WA), occupation of the women(WO), education level of the women (WE), and number of children (NC). The fitted model for odd ratio of the use of TFP method by women, where $\mathrm{p}$ is the probability of use of TFP by women, is shown in equation (1). The estimates in (1) tell the relationship between the independent variables and the dependent variable and consequently the amount of increase (or decrease if the sign of coefficient is negative), these are not interpreted as in a normal regression equation. The coefficients of each category of the variable in the model are the odd ratios of the corresponding category with respect to the lowest category of the same variable (according to the way we set in SPSS), the interpretation is given based on odd ratios. 
$\mathrm{p} /(1-\mathrm{p})=2.552+1.331 *$ Knowledge level(FK1) $+2.613 *$ Knowledge level(FK2)+ $1.245^{*}$ Seeking advices from PHM(AP1) + 0.751*Attend to well women Clinic $(\mathrm{AW} 1)+0.700 *$ Attend to well women Clinic(AW2) $+0.728 *$ Religion(RR1) $+1.854 *$ Ethnicity $(\mathrm{RE} 1)+$ $0.147 *$ Decision to use FP(FD1) $+0.294 *$ Decision to use FP(FD2) $+4.264 *$ Decision to use FP(FD3) + 0.722* Husband's occupation $(\mathrm{HO} 2)+0.660 *$ Husband's occupation(HO3) $+1.487 *$ Women's Age(WA1) + 2.339*Women's Age(WA2) + 1.881*Women's Age $($ WA3 $)+1.248 *$ Women's occupation $($ WO2 $)+1.380 *$ Women's education(WE2) + $2.436 *$ Women's education(WE3) $+1.423 *$ Number of children $(\mathrm{NC} 1)+3.983 *$ Number of children(NC2) + 1.396*Districts by FP usage(DU1) + 1.769*Districts by FP usage(DU2) $+1.237 *$ Wealth Quantile(WQ1) + 1.204*Wealth Quantile(WQ2)

Results indicate that, the odds of the usage of TFP are 1.331 times and 2.613 times higher respectively among women who have good knowledge and moderate knowledge on family planning (FP) than the women with poor knowledge on FP. The odds of the usage of TFP is 1.245 times higher among women who do not seek advice from the public health midwife compared to the women who seek advice. The odds of the usage of TFP is 1.854 times higher among Sinhalese women compared to the Burger women. The odds of the usage of TFP with the decision to use family planning taken by both husband and wife is 4.264 times higher compared to the decision taken through the influence of a public health midwife (PHM).. The odds of the usage of TFP are 1.487 times, 2.339 times and 1.881 times higher respectively among women who are in the ages of 42- 50 years, 33- 41 years and 24- 32 years than the women who are in the ages of 15- 23 years.

The odds of the usage of TFP among women who are working as clerical, sales, industry and machine related workers are 1.248 times higher than the women who are unemployed while all the other variables in the model are fixed. The odds of the usage of traditional family planning among the women who are childless and women who have 1 to 2 children are respectively 1.423 times and 3.983 times higher than the women who have 3 children or above.

\section{Conclusions and Suggestions}

Analyzing all variables simultaneously is better than analysing variables separately to identify influential factors. When all the variables are considered simultaneously using the binary logistic regression model, knowledge on FP, seeking advice from PHM, attendance in well women clinic, religion, ethnicity, decision to use FP, husband's occupation, women's age, women's occupation, women's education level, number of children, districts by FP usage and wealth quantile are identified as significantly associated factors with the usage of traditional family planning. The overall predictivity power of the final model is $82.9 \%$. The values of odd ratio confirmed that the factors which influence the use of TFP are the number of children in the family and the education level of women.

The identified factors are geared towards providing a contemporary, robust evidence base, so that key population groups in need of contraceptive services can be targeted more 
effectively and efficiently. The Government and the Ministry of Health should pay more attention to the counselling and promotion of family planning programmes among women who use traditional family planning methods in Sri Lanka by providing them precise practical knowledge related to the use of modern methods. The Family Health Bureau and The Family Planning Association of Sri Lanka should organize family planning awareness programmes which should be conducted by Public Health midwives who approach educated working women in Sri Lanka. It is essential to promote awareness programmes for working women in their places of employment.

It is suggested to promote new family planning methods among the women irrespective of age and to organize sexual and reproductive health and family planning awareness programmes for the teenage girls and boys at their schools.

\section{References}

Gunawardane, N., \& Hettiarachchi, J. (2012). Factors related to choice of modern vs traditional contraceptives among women in rural Sri Lanka. Sri Lanka Journal of Obstetrics and Gynaecology, 20-25.

Karunaratna (2020). Dissertation submitted for the M. Sc. in Business Statistics, University of Moratuwa.

Shaw, D. (2010). The ABC's of Family Planning. Geneva: World Health Organization.
Singh, S., Wulf, D., \& Jones, H. (1997). Health professionals' perceptions about induced abortion in south central and southeast Asia. International Family Planning Perspectives, 23 -35.

Sri Lanka Demographic and Health Survey (2016), Department of, Census and Statistics, Sri Lanka.

United Nations. (2019). Contaceptive Use by Method 2019 - Data Booklet. New York: United Nations.

United Nations. (2017). World Family Planning Highlightes. New York: Department of Economic and Social Affairs - United Nations.

World Health Organization-WHO. (2020). Concepts and Definitions of Contraseptives. Geneva: World Health Organization. 